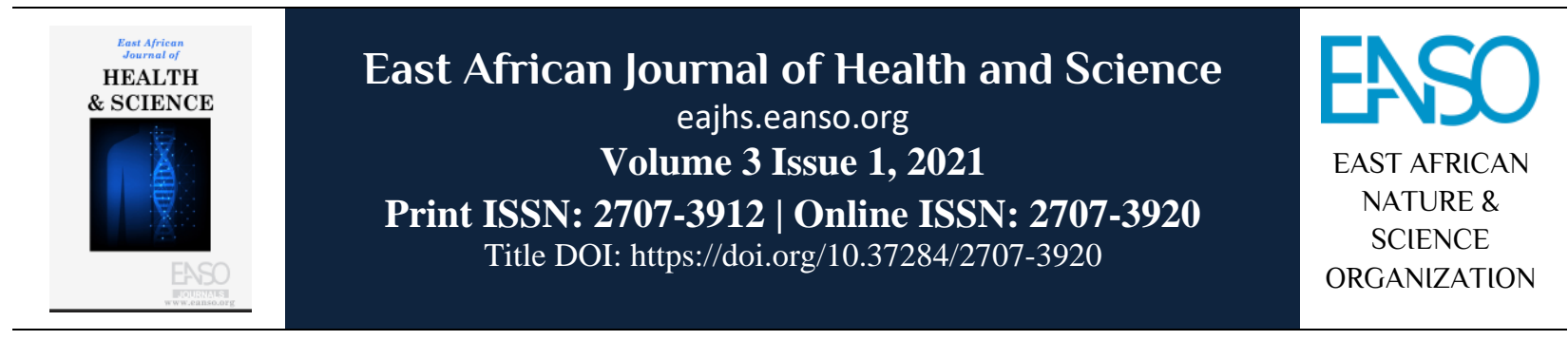

Original Article

\title{
Aspirations versus Reality: Exploring Factors Affecting Meaningful Youth Participation in Sexual and Reproductive Health and Rights Programme in Rural Kenya
}

\author{
Humphres Evelia ${ }^{* 1}$, Phoebe Ndayala ${ }^{2}$, Anna Page ${ }^{3}$, Charles O. Wafula, Judith Westeneng ${ }^{3}$, \\ Johnstone Kuya $a^{5}$ \& Faith Chesire ${ }^{4}$ \\ ${ }^{1}$ Globus Associates Questream, P. O. Box 745 - 00100, Nairobi, Kenya. \\ ${ }^{2}$ Kenyatta University, P. O. Box 43844 - 00100, Nairobi, Kenya. \\ ${ }^{3}$ Rutgers, P. O. Box 9022, 3506, Utrecht the Netherlands. \\ ${ }^{4}$ Tropical Institute of Community Health and Development (TICH), Kisumu. \\ ${ }^{5}$ Kenya Royal Dutch Embassy Riverside Nairobi Kenya. \\ *Author for correspondence email: hevelia@gmail.com.
}

Article DOI: https://doi.org/10.37284/eajhs.3.1.297

\section{Date Published: ABSTRACT}

15 March 2021 This paper presents the results of an implementation research of a pilot intervention, mainstreaming meaningful youth participation in a health care

Keywords: management system in Western Kenya with the aim to address adolescent

Meaningful Youth

Participation,

Adolescent Sexual,

Reproductive Health,

Rights,

Youth Involvement,

Implementation

Research, sexual and reproductive health and rights (SRHR). This qualitative case study included 29 key informant interviews and 13 focus group discussions conducted in five community health units across four counties. The results demonstrate positive attitudes towards the principle of youth participation, yet, also a mismatch between the aspirations of young people to be active decisionmaking agents and the actual roles and responsibilities assigned to them. This paper further identifies factors that inhibit and enable effective youth

Kenya, migration, gender); organisational (such as guidelines and structures, financial

Community Health

Strategy. support, and political interference) and societal (norms seeing SRHR as taboo and young people as unequal to adults), and formulates recommendations to address these.

\section{APA CITATION}

Evelia, H., Ndayala, P., Page, A., Wafula, O. Charles., Westeneng, J., Kuya, J., \& Chesire, F. (2021). Aspirations versus Reality: Exploring Factors Affecting Meaningful Youth Participation in Sexual and Reproductive Health and Rights Programme in Rural Kenya. East African Journal of Health and Science, 3(1), 31-44. https://doi.org/10.37284/eajhs.3.1.297.

31 This work is licensed under a Creative Commons Attribution 4.0 International License. 


\section{CHICAGO CITATION}

Evelia, Humphres, Phoebe Ndayala, Anna Page, Charles O. Wafula, Judith Westeneng, Johnstone Kuya, and Faith Chesire. 2021. "Aspirations versus Reality: Exploring Factors Affecting Meaningful Youth Participation in Sexual and Reproductive Health and Rights Programme in Rural Kenya". East African Journal of Health and Science 3 (1), 31-44. https://doi.org/10.37284/eajhs.3.1.297.

\section{HARVARD CITATION}

Evelia, H., Ndayala, P., Page, A., Wafula, O. C., Westeneng, J., Kuya, J., and Chesire, F. (2021) “Aspirations versus Reality: Exploring Factors Affecting Meaningful Youth Participation in Sexual and Reproductive Health and Rights Programme in Rural Kenya”, East African Journal of Health and Science, 3(1), pp. 31-44. doi: 10.37284/eajhs.3.1.297.

\section{IEEE CITATION}

H. Evelia, P. Ndayala, A. Page, O. C. Wafula, J. Westeneng, J. Kuya, and F. Chesire, "Aspirations versus Reality: Exploring Factors Affecting Meaningful Youth Participation in Sexual and Reproductive Health and Rights Programme in Rural Kenya", EAJHS, vol. 3, no. 1, pp. 31-44, Mar. 2021.

\section{MLA CITATION}

Evelia, Humphres, Phoebe Ndayala, Anna Page, Charles O. Wafula, Judith Westeneng, Johnstone Kuya, and Faith Chesire. "Aspirations versus Reality: Exploring Factors Affecting Meaningful Youth Participation in Sexual and Reproductive Health and Rights Programme in Rural Kenya". East African Journal of Health and Science, Vol. 3, no. 1, Mar. 2021, pp. 31-44, doi:10.37284/eajhs.3.1.297.

\section{INTRODUCTION}

Over the last two decades, youth participation has grown in prominence across international sexual and reproductive health and rights (SRHR) programmes (Villa-Torres \& Svanemyr, 2015; Miedema et al., 2011). The focus has widely been on 'meaningful' participation, which actively engages young people in all phases of development and implementation of policies, programmes and services that affect their lives (Howard et al., 2002). Some studies describe meaningful youth participation (MYP) as 'decision-making by young people that involves meaning, control, and connectedness' (Oliver et al., 2006), while others emphasise the importance of young people being able to "participate on equal terms with adults, or work independently in organisations and in all stages of programming and policy-making: design, implementation, monitoring and evaluation (CHOICE for Youth and Sexuality \& YOUACT, 2018).

Perhaps the most well-known typology analysing the 'meaningfulness' of participation is Hart's (1992) seminal 'Ladder of Participation' which builds on the work of Arnstein (1969) to acknowledge young people and adults' differing experiences of societal power and control (Arnstein, 1969; Hart, 1992). Hart's presents a linear series of types of (non-)participation, ranging from 'manipulation' to 'child-initiated shared decisions with adults', where the 'highest' types of participation are assumed to be the most desirable (Hart, 1992). Rejecting the hierarchical conception implied in ladder forms, Treseder's 'Degrees of Participation' identifies five distinct but equal forms of participation: (a) assigned, but informed, (b) consulted and informed (c) adult-initiated, shared decisions with children, (d) child-initiated and directed and (e) child-initiated, shared decisions with adults (Treseder, 1997 cited in Wong et al., 2010). CHOICE for Youth and Sexuality and YOUACT's (2018) 'Flower of Participation', specific to youth SRHR programmes, directly adopts Treseder's five types of participation as five 'petals' and reintroduces Hart's three forms of nonparticipation; manipulation, decoration and tokenism as 'leaves' The CHOICE model also crucially recognises that different forms of participation can and do exist within the same programme.

This paper explores MYP within a youth SRHR programme in rural Western Kenya. It seeks to identify the form of participation achieved, understand barriers and enablers to MYP within the case study. Practitioners and scholars have previously identified a number of critical factors enabling or hindering MYP. At an organisational level, 'mechanisms must be in place that allows young people to have an active role, in which their voice is heard and respected (CHOICE for Youth

32 This work is licensed under a Creative Commons Attribution 4.0 International License. 
and Sexuality \& YOUACT, 2018). This is more likely to be achieved in a youth-friendly environment, accessible language and tools which facilitate young people's full understanding is used; when safe spaces which enable young people to express and share their opinions and experiences are provided; and, when flexible opportunities for involvement which fit with school, work and/or caring commitments are offered. Additionally, organisational policies should integrate the involvement of young people, for instance, specifying the proportion of young people on organisational boards. Key among the perquisites of MYP is that both young people and adults should feel valued, respected, safe, encouraged and supported (CHOICE for Youth and Sexuality \& YOUACT, 2018; Campbell et al., 2009).

Moreover, financial incentives are vital in facilitating MYP, particularly as young people often participate on a voluntary basis. Fair compensation for volunteering should be factored in; at the minimum, the compensation should cater for travel and meals and refreshments (CHOICE for Youth and Sexuality \& YOUACT, 2018). In addition, material incentives can also be factored in; these may include training courses, certificates and attendance at international and national events (Campbell et al., 2009). A broader view of incentives for MYP includes meaningful public recognition and a sense of belonging (Campbell et al., 2009; Cornish, 2006).

Studies support the crucial role adults play in facilitating MYP (Mchakulu, 2007; Campbell et al., 2009; CHOICE for Youth and Sexuality \& YOUACT, 2018). Commitment from adults to support young people to meaningfully participate and respect young people as equals are all vital in achieving MYP (CHOICE for Youth and Sexuality \& YOUACT, 2018). Drawing on Freire (1970), Wong et al. argue that "youth empowerment requires adults to be actively involved in fostering conditions and opportunities for youth to develop critical consciousness' (Freire, 1970; Wong et al., 2010). Organisations and individual adults may need capacity building in working with and supporting young people in order to enable them to play this role (Campbell et al., 2009; Finlay, 2010).
However, positive structures established at an organisational level can be undermined by broader societal factors limiting youth participation. Participatory approaches may face resistance if their aims are deemed a threat to existing cultural norms and/or interpersonal relations. Adults may be reluctant to recognise the potential value of young people and be unwilling to see young people as equals, seeing young people as lazy or inferior to adults. Adult denial of youth sexuality can hinder youth involvement in SRHR programmes (Campbell et al., 2009).

Despite recognition of these factors impacting MYP at organisational and societal levels "much work remains to be done in expanding our understandings of the psycho-social factors that are most likely to enable effective youth participation and on how to promote the development of these factors from one situation to the next' (Campbell et al., 2009). This paper takes a case study approach to explore indepth the factors affecting MYP based on a pilot intervention that mainstreamed MYP in health care management systems of five Community Health Units (CHUs) in Western Kenya. Drawing from reproductive international experience and expertise in the execution of the pilot project, findings and recommendations from this study are expected to find relevance beyond the case study.

\section{INTERVENTION: ACCESS SERVICES AND KNOWLEDGE PROGRAMME}

The intervention was implemented under the Access Services and Knowledge (ASK) programme, a 3year programme (2013-2015) aiming to improve adolescent sexual and health and rights (SRHR) by providing SRHR education and information, promoting SRHR service uptake amongst 10-24year-olds, including marginalised groups, and creating an enabling environment through advocacy and community awareness-raising. ASK programme was funded by the Dutch Ministry of Foreign Affairs. It was a joint effort of eight organisations comprising of Rutgers (lead), Simavi, Amref Flying Doctors, CHOICE for Youth and Sexuality, dance4life, Stop AIDS Now!, the International Planned Parenthood Federation (IPPF), and Child Helpline International (CHI). 
ASK was implemented in 7 countries, namely Ethiopia, Ghana, Indonesia, Kenya, Pakistan, Senegal, and Ugand $a$. Meaningful youth participation was an integral part of the programme. The pilot project was implemented by a local NGO, Tropical Institute of Community Health and Development (TICH) with the support of Simavi a Dutch-based NGO that strives for a world in which women and girls are socially and economically empowered and pursue their rights to live a healthy life free from discrimination, coercion and violence. TICH brings together academicians, professionals and practitioners in Health systems and development from diverse backgrounds to pool their skills, expertise and experience to undertake capacity building, research and service delivery. Through its programs, TICH facilitates poverty reduction, health care and development by bridging training with service delivery programs, focusing on the needs of the most vulnerable members of the society. It develops tests and disseminates innovative and effective models of communitybased initiatives through research. The pilot project was implemented in Western Kenya promoting the involvement of young people in existing health care management structures and positioning them as codeliverers of the programme.

Since 2002, TICH has worked in partnership with the Kenyan Ministry of Health (MoH) to implement the Community Health Strategy (CHS) in nine counties in Western Kenya (Kisii, Migori, Homabay, Kisumu, Siaya, Kakamega, Busia, Bungoma and Trans Nzoia). The strategy emphasises the importance of community participation in health service delivery and decision making. Assessment of the CHS implementation had revealed notable gaps, which included a lack of youth representation in Community Health Committees (CHCs) and consideration of youth sensitivities and needs when recruiting key service providers Community Health Workers (CHWs). As such, it was clear that youth SRHR issues were not adequately addressed in the CHS or health systems prompting $\mathrm{TICH}$ to initiate the engagement of young people in the health care management system as a key strategy in tackling these challenges.

The pilot project focused on proving the young people with a forum to voice their health issues to the Health Care Management Team (HCMT) by integrating youth representation into the Community Health Committees (CHCs) in the community health units (CHUs). A community health unit (CHU) is the lowest unit of health system organisation in Kenya consisting of approximately 10 villages and an average population of 5,000 people. A village is the smallest administrative unit in Kenya, with an average of 5,00 people. In Western Kenya, young people aged 15-24 were mobilised into youth groups as part of the ASK programme. TICH trained youth group members on CHU structures, skills including leadership, governance, issue identification and specification, programme design, implementation and monitoring and evaluation. Each group elected officials and representatives developed annual plans and assigned roles to individual members.

The project aimed to integrate youth representation in the Community Health Committees (CHCs) in the $170 \mathrm{CHUs}$. Roles took on by young people in the CHCs included; managing computer-based SRHR information centres; conducting outreach services in collaboration with health facilities; advocacy with policymakers and implementers; undertaking household visits; conducting youth-led dialogue days where young people come together to discuss factors affecting their access to health care services; and, running community campaigns to sensitise community members to support youth access to SRHR information and services. In addition, the youth groups met monthly to prioritise and ratify key issues to be presented to Community Health Committees (CHCs) by the youth representatives. Through the ASK programme, young people were also represented in the different levels of the health system, as outlined in Table 1 below. 
Table 1: Overview of youth involvement in the different levels of the health care management system

\begin{tabular}{|c|c|c|c|}
\hline $\begin{array}{l}\text { Level/ } \\
\text { administrative } \\
\text { unit }\end{array}$ & $\begin{array}{l}\text { Description of the Health } \\
\text { System }\end{array}$ & Youth involvement & Cycle of meetings \\
\hline County & $\begin{array}{l}\text { County Health Management } \\
\text { System }\end{array}$ & Not included in ASK & \\
\hline Sub-county & $\begin{array}{l}\text { Health Management } \\
\text { Administration }\end{array}$ & 1 youth representative & $\begin{array}{l}\text { Monthly meetings, } \\
\text { youth representatives } \\
\text { invited quarterly }\end{array}$ \\
\hline Division & $\begin{array}{l}\text { Represents approx. } 3 \text { health } \\
\text { facilities or } 8-9 \text { sub-locations }\end{array}$ & $\begin{array}{l}1 \text { youth representative per health } \\
\text { facility = approx. } 3 \text { in total }\end{array}$ & Quarterly meetings \\
\hline Health Facility & $\begin{array}{l}\text { Health Facility Management } \\
\text { Team, representing approx. } 3 \\
\text { sub-locations }\end{array}$ & $\begin{array}{l}1 \text { youth representative per sub- } \\
\text { location = approx. } 3 \text { in total }\end{array}$ & Quarterly meetings \\
\hline \multirow[t]{2}{*}{$\begin{array}{l}\text { Sub-location } \\
\text { (Community } \\
\text { Health Unit) }\end{array}$} & $\begin{array}{l}\text { Community Health Committee, } \\
\text { representing approx. } 16 \\
\text { villages }\end{array}$ & 1 youth representative & $\begin{array}{l}\text { Quarterly dialogue } \\
\text { days }\end{array}$ \\
\hline & & $\begin{array}{l}\text { Youth group at sub-location } \\
\text { level, including all youth health } \\
\text { volunteers + a governance body } \\
\text { (chair, secretary, etc.) }\end{array}$ & Monthly meetings \\
\hline Village & & $\begin{array}{l}1 \text { youth health volunteer per } \\
\text { village }\end{array}$ & Monthly meetings \\
\hline
\end{tabular}

\section{METHODOLOGY}

This study adopted a cross-sectional qualitative research design in five Community Health Units (CHUs) that participated part in the ASK programme. The five research sites were: Shibembe and Mutoma in Kakamega County, Madibo in Busia County, Omia Malo in Siaya County and Gem Nam in Kisumu County. These sites were purposively selected since they were the forerunners of the 170 CHUs in integrating youth participation in their CHCs. Each of the five CHUs sampled had been sensitised on MYP and had accepted a youth representative on the CHC. A total of 30 semistructured Key Informant Interviews (KIIs) were conducted with five Division Public Health Officers, five managers of participating health facilities, five assistant chiefs; five religious leaders; five community health committee chairpersons; and five youth representatives. Furthermore, 14 focus group discussions (FGDs) were conducted: five with youth group members, five with youth health volunteers (YHVs), one with Community Health Extension Workers (CHEWs), and three with community members. Based on preliminary data analysis, participatory workshops were held in three randomly selected study sites out of the five study sites sampled in the first phase to discuss findings and formulate recommendations. These workshops, each with an average of 75 participants brought together community members, health care management team members, young people, and representatives of implementing organisation TICH.

The semi-structured interview guides were translated from English into Kiswahili and local languages and pre-tested. As a research institute, TICH was responsible for the recruitment and training of data collectors. However, as TICH also implemented the intervention, independent consultants were responsible for the research proposal, instrument development, analysis and reporting. The consultants were also involved in fieldwork to ensure independent data collection. All KIIs and FGDs were transcribed and coded using a coding framework and NVivo 10 software. Signed consent for participation in the study was obtained from all participants above 18 years. Young people aged below 18 years provided assent to participate in the study after getting parental consent. Ethical

35 | This work is licensed under a Creative Commons Attribution 4.0 International License. 
clearance was granted by AMREF Scientific Ethics and Review Committee in Kenya.

\section{RESULTS}

The results are divided into three main sections. Firstly, we discuss different perceptions of the importance of meaningful youth participation. This is followed by a comparison of the roles young people aspired to perform and those they actually fulfilled. Lastly, we analyse the barriers and enablers to meaningful youth participation at an individual, organisational and community level.

\section{Perceptions on the Importance of MYP}

In all five CHUs, youth and adult respondents had positive attitudes towards involving youth in Community Health Committees (CHCs):

'...having youth representatives will enable them [young people] to share their views with their representatives who can address these factors at a higher level' (KII, youth representative).

$\mathrm{CHC}$ members felt that having youth representation on the CHC was important as it would enable a better understanding of the needs of young people as captured in the verbatim reports. Young people were seen as better positioned to represent their peers due to shared experiences, language and perspectives. Moreover, adult respondents saw young people as more open to discuss SRHR issues with their peers than adults and thus able to bridge the age gap and communication barrier between young people and adults. This view was echoed by youth representatives:

'Because youths are shy to freely talk about their SRHR issues with adults, having youth representatives will enable them to share their views with their representatives who can address these factors at a higher level' (KII, youth representative).

CHC members from two localities also described MYP as a form of mentorship which prepared young people to take up adult roles in future. This was seen as helping to ensure continuity of $\mathrm{CHC}$ activities as young people potential future replacements or stand-ins for current $\mathrm{CHC}$ members:

'I feel it is okay for youths to be given an opportunity because they are the leaders of tomorrow and will take leadership when adults retire.' (FGD, community member);

'CHEWs who are currently there are old. If we don't have the young people, who will pick from them when they retire?' (FGD, Community Health Extension Workers).

\section{Roles of Young People}

Despite a consensus on the value of MYP in principle, a comparison between the roles young people were willing to fulfil and those they actually undertook demonstrates a mismatch. Youth representatives expressed a desire to take on key leadership and decision making roles on the CHC such as Chair or Committee Organizing Secretary, as well as agenda-setting and coordination responsibilities such as event organisation; project design; planning, management and supervision (particularly of adolescent reproductive health programmes); proposal writing and resource mobilisation; oversight of resource utilisation and health care management issues; and advocacy especially on youth SRHR issues.

Generally, the roles performed by youth representatives can be summarised into two main categories: health promotion/peer education and supportive roles. These roles were assigned by the CHC leaders who were adult community representatives, local leaders or state officials. Health promotion/peer education tasks included health education; awareness-raising and mobilisation through role-play, drama and social media activities; door to door campaigns; health talks; peer counselling; activating peers for 'community clean-ups'; distributing commodities such as mosquito nets; providing referrals to health services; and carrying out client follow-ups, household registration, and immunisation. The supportive roles mainly focused on facilitating $\mathrm{CHC}$ operations, for example, driving health facility vehicles, secretarial tasks, organising community health events, taking minutes, questionnaire

36 | This work is licensed under a Creative Commons Attribution 4.0 International License. 
administration and community health data collection.

Youth representatives felt they were mainly assigned peripheral and administrative tasks that did not accord them voting rights on key decisions or give them a voice or power to set and influence budgets, health agenda or decisions of the CHC. Youth representatives expressed a desire to be given more key decision-making roles and to be provided with more opportunities for involvement in the CHC.

\section{Barriers and Enablers to MYP}

The results demonstrated three levels of factors influencing meaningful youth participation: individual, organisational, and contextual. Table 2 provides an overview of the main results.

\section{Table 2: Overview of barriers and enablers for MYP at different levels}

\begin{tabular}{|c|c|c|c|}
\hline Level & Type & Barrier & Enabler \\
\hline \multirow[t]{3}{*}{$\begin{array}{l}\text { Individual- } \\
\text { level }\end{array}$} & $\begin{array}{l}\text { Social } \\
\text { characteristics }\end{array}$ & $\begin{array}{l}\text { - Lack of knowledge, skills and } \\
\text { technical know-how; low education } \\
\text { - Inferiority complex } \\
\text { - Undisciplined \& lazy } \\
\text { - Prone to substance abuse } \\
\text { - Young age } \\
\text { - Being female } \\
\text { - Mobile / likely to migrate }\end{array}$ & $\begin{array}{l}\text { - Education; training received; } \\
\text { Prior experience; technical } \\
\text { knowhow; quick learners } \\
\text { - Energetic, hardworking; } \\
\text { disciplined } \\
\text { - Being a 'native.' } \\
\text { - Political objectiveness and non- } \\
\text { alignment }\end{array}$ \\
\hline & $\begin{array}{l}\text { Role } \\
\text { performance }\end{array}$ & $\begin{array}{l}\text { - Unwillingness to volunteer } \\
\text { - Lacking commitment } \\
\text { - Not following procedures/rules }\end{array}$ & $\begin{array}{l}\text { - Willingness to volunteer } \\
\text { - Respecting CHC procedures } \\
\text { - Act as a role model }\end{array}$ \\
\hline & Economic & $\begin{array}{l}\text { - Lack of income / resources / } \\
\text { unemployment }\end{array}$ & \\
\hline \multirow[t]{2}{*}{$\begin{array}{l}\text { Organisational/ } \\
\text { HCMT }\end{array}$} & Governance & $\begin{array}{l}\text { - Lack of legal } \\
\text { backing/policies/guidelines for MYP }\end{array}$ & $\begin{array}{l}\text { - Clear guidelines and structures } \\
\text { - Mentoring youth } \\
\text { representatives } \\
\text { - Youth-friendly adults }\end{array}$ \\
\hline & Economic & $\begin{array}{l}\text { - Inadequate or mismanagement of } \\
\text { resources / understaffing }\end{array}$ & - Providing stipends \\
\hline $\begin{array}{l}\text { Community- } \\
\text { level }\end{array}$ & Cultural & $\begin{array}{l}\text { - SRHR as taboo (partly due to } \\
\text { religious ideologies) } \\
\text { - Gender norms } \\
\text { - Values on age } \\
\text { - Inter-clan supremacy }\end{array}$ & \\
\hline
\end{tabular}

\section{Individual Level}

At the individual level, we distinguish three different types of barriers and enablers: 1) (perceived) characteristics of the young people; 2) attitude and role performance; and 3) economic issues. Adult respondents widely cited a broad range of individual characteristics of young people, which served to limit their ability to meaningfully participate. Adults in four study sites mentioned young people's lack of knowledge or ignorance on SRHR as a key barrier; low education attainment was identified in three $\mathrm{CHCs}$, while in two $\mathrm{CHCs}$, a lack of skills or technical knowhow and a feeling of inferiority was seen to deter young people from making useful contributions to $\mathrm{CHC}$ discussions.

'Some of them are ignorant because they do not know what is expected of them .... and others think we won't accept them.' (KII, CHC Chairperson).

Moreover, adults suggested some young people are undisciplined (cited in three CHUs) and/or prone to substance abuse (cited in two CHUs), rendering them unfit to perform the roles assigned to them.

37 | This work is licensed under a Creative Commons Attribution 4.0 International License. 
'If one is undisciplined, he cannot be allowed to work with us. Maybe he has been brought on board and he wants to act like he knows more than the elders he found there. He even insults them that they cannot think because of their old age...' (FGD, community members).

Conversely, young people believed they had the capacity needed to adequately perform roles assigned to them as they had received relevant training from $\mathrm{TICH}$ and other organisations implementing the ASK Programme; because they had prior experience working as Community Health Volunteers (CHVs) or on other health engagements and/or because they had completed more years of formal education than adult $\mathrm{CHC}$ members. Moreover, adults in the CHC identified communication barriers with young people, especially in young people's use of slang language ('Sheng'). Young people, on the other hand, felt that their use of slang increased their acceptability to their peers and meant they could effectively act as a link between youth group members and CHCs.

Both adults and young people perceived young age as an inhibitor to MYP in the CHC (cited in three $\mathrm{CHCs}$ ). Adults asserted that young people's age resulted in a generation gap which interfered with free and open communication between the adult CHC members and young people. On the other hand, young people described their youthfulness as inhibiting MYP since it caused adults to look down upon them and not take their contributions for granted. Young people believe that being youthful made them more energetic and committed to contributing their time to perform assigned roles.

Lack of community support in the area of sexual reproductive health makes it hard for youth to speak about sexual reproductive health issues. You want to address a certain issue to the elders about reproductive health issues and they despise you because you are young and that will dent your image instead' (KII, youth representative, $\mathrm{CHC}$.)

Gender bias was observed in adults' preferences of which young people to involve in the CHC. Some adult $\mathrm{CHC}$ members believed that female youth representatives were soon to be married, which would take them away from the community and disrupt the continuity of $\mathrm{CHC}$ activities. Female youth representatives were therefore seen as 'outsiders' who could not contribute meaningfully and did not deserve to be assigned critical roles even if they were willing and possessed the requisite qualities.

Some of these individual characteristics have a direct influence on barriers within the second category: attitude and role performance. Adult respondents asserted that young people exhibited negative attitudes towards community work and were thus unwilling to volunteer. They saw young people as lazy, constantly seeking better opportunities, making it difficult to sustain youth engagement. In one site, adult committee members described young people as lacking commitment and not ready to follow committee operational rules and procedures. As such, they did not meet their obligations to the $\mathrm{CHC}$.

Finally, in the third category, economic issues, several adults described young people as always expecting financial compensation for performing $\mathrm{CHC}$ responsibilities

'The challenge is that they (youth) always want handouts every time and also do not like voluntary work ...' (KII, Assistant Chief, CHU);

'Some of them will be wishing to be given some stipend. Most youths are not employed and if you keep them here for free, they will run away...' (KII, Health Facility In-charge).

Conversely, young people felt that adults CHC members sought free services from young people despite being able to afford to pay them. Perhaps underlying young people's requests for funding, respondents in all five study sites alluded to the low economic status of the youth representatives. The voluntary nature of participation on the $\mathrm{CHC}$ implied that youth representatives who lacked personal financial resources were often unable to meet logistical requirements such as transport to attend $\mathrm{CHC}$ meetings and activities. Furthermore, unemployment among youth within the CHUs led to migration in search for jobs elsewhere which limited youth participation in the CHCs.

In addition to these barriers, the findings also highlighted a number of individual enablers to

38 This work is licensed under a Creative Commons Attribution 4.0 International License. 
promoting MYP in the health care management system at the community level. Good educational attainment was, for instance, perceived as a contributor by the adult representatives in four out of the five CHUs. A good education was perceived to enhance youth representatives' understanding of $\mathrm{CHC}$ operation and procedures and their ability to make useful contributions. Adult $\mathrm{CHC}$ members revealed they preferred youth representatives who were 'quick learners' Three out of five CHUs identified being hardworking and energetic and possessing skills and technical knowhow as enhancers to MYP. These factors were seen as critical in young people being accepted on $\mathrm{CHCs}$.

'Some of them [young people] are educated and I think from their educational background they are able...They are trained.... English command- their language is good... Some of them if not all are computer literate ... They have good networking with stakeholders from different organisations.' (FGD, Community Health Workers)

Other characteristics that can positively contribute to MYP, according to the adult members, include self-discipline, good character and behaviour of youth representatives. In one $\mathrm{CHU}$, adults stated that discipline among the youth representatives increased their acceptability among the CHC members and increased the probability of them being assigned roles on the $\mathrm{CHC}$, and their voice is taken seriously. Willingness to volunteer was also cited as an enabling factor to MYP.

The adult respondents viewed 'being a native of the CHU' as a key enhancer for MYP. Being 'native' was seen to foster community acceptance as young people were seen as 'an insider rather than an 'outsider', able to easily understand the sociocultural context and dynamics of the CHU. Other key enhancers of MYP as perceived by adults include young people's perceived political objectivity and non-alignment, described as enhancing committee harmony and strengthening adult confidence in young people and their participation; youth proactivity, availability and willingness to take on assigned committee tasks; active participation, and respect for committee procedures.

39 This work is licensed under a Creative Commons Attribution 4.0 International License.
Youth representatives indicated having the potential and ability to act as a role model in the community for peers as a key enhancer to MYP. Youth representatives in one $\mathrm{CHU}$ described social acceptance amongst peers as an enhancement to their performance as it gave them the mandate needed to represent young people on the $\mathrm{CHC}$ and to advocate youth SRHR priorities. Other youth representatives described having an interest in community work and improving youth SRHR as vital in being able to perform assigned $\mathrm{CHC}$. Findings also show that community recognition of the contributions of young people to $\mathrm{CHCs}$ through the presentation of awards in a 'baraza' (community meeting) motivated young people and enhanced MYP.

\section{Organisational/CHC level}

At the organisational level, we have categorised the results in two categories: 1) governance; and 2) economic issues. In terms of governance, participants in three sites asserted the lack of policy guidelines, laws, or regulations on embedding youth representation in CHUs as a reason for the persistent dominance of CHC members who saw young people as inferior in terms of maturity and experience and therefore not entitled to key $\mathrm{CHC}$ responsibilities. Such members were often willing to allow young people to air their views and vote but did not accept young people taking up key decisionmaking positions.

Conversely, good CHC governance and clear structures for youth participation served to increase young people's confidence in the committee. Assigning young people roles on the $\mathrm{CHC}$ served to enhance their sense of self-worth, motivation and self-confidence, which in turn enhanced their performance. Opportunities to take on meaningful roles were provided by some adult $\mathrm{CHC}$ members who agreed to relinquish some of their roles to motivated young people. The presence of 'youthfriendly' adults who accommodated and supported young people to take up assigned roles positively contributed to MYP. Being youth-friendly was reported to help young people allay their fears of participation, demystifying assigned roles and 
increasing their confidence to articulate their SRHR concerns.

At an economic level, adults described limited CHC resources as a barrier to both MYP and to $\mathrm{CHCs}$ focusing on youth SRHR issues. In contrast, young people purported that $\mathrm{CHCs}$ has adequate resources, but mismanagement resulted in limited resources for youth-friendly services. Finally, providing youth representatives with stipends, especially after assignments, was identified as a key enhancer for MYP, seen to encourage and motivate young people to participate in $\mathrm{CHC}$ activities.

\section{Community-level}

At the community level, the most cited barriers to MYP were cultural. Firstly, in four sites, participants explained that religious teachings and ideologies did not allow young people to discuss SRHR issues, use SRHR services or get information on SRHR. This may have influenced the decision and prioritisation of youth SRHR on the health care management committees, hence affecting young people's involvement. The taboo of young people discussing SRHR issues was exacerbated by both gender and age. Respondents in two sites suggested cultural norms and taboos prohibited young women from discussing SRHR issues in the presence of men, making it difficult to engage young women in the CHC. In four CHUs, young people irrespective of gender were prohibited from discussing SRHR issues, especially in the presence of adults, making young people fearful of addressing SRHR issues in $\mathrm{CHC}$ fora.

Lack of community support in the area of sexual reproductive health makes it hard for youth to speak about [it]. You want to address a certain issue to the elders about reproductive health issues and they despise you because you are young and that will dent your image instead.' (KII, youth representative).

Cultural values related to age presented a broader challenge than simply young people's ability to discuss SRHR issues. We also found that young people and adults sometimes had a negative view of one another in general. In two sites, adult $\mathrm{CHC}$ members suggested young people saw adults as backward, illiterate and ignorant about youth SRHR issues. Young people confirmed that they felt some adult committee members were not suited to their positions. On the other hand, young people felt that adults had a negative attitude towards youth representatives because they feared competition from young people who were more qualified to take up CHC positions and preferred to maintain the status quo.

Inter-clan supremacy and nepotism among CHC members were also seen as inhibiting MYP. Young people in one site purported that $\mathrm{CHC}$ leaders appointed only members of their own clan to the committee, hence disempowering other clans and limiting participation opportunities. Furthermore, bias based on political allegiance and party affiliation was reported to affect appointments. In two of the five community health units, such bias was described as leading to wrangling and disagreements during committee, thereby diverting attention from meaningful youth participation. Table 2 provides a summary overview of barriers and enablers of MYP at different levels.

\section{DISCUSSION}

The findings have illustrated barriers and enablers for MYP at individual, organisational and societal levels. At an individual level, adults cited young people's lack of knowledge, skills and motivation and frequent unemployment as barriers to MYP. Conversely, being educated, hardworking, disciplined, respectful, and a role model were seen as enablers. At an organisational level, clear guidelines and structures, being youth-friendly and financial support through stipends were seen as enablers to MYP. These factors reflect key success criteria as identified by CHOICE (CHOICE for Youth and Sexuality \& YOUACT, 2018). Barriers at the organisational level included a lack of policies on MYP and economic mismanagement. Underpinning many of the barriers at a cultural level were societal norms seeing SRHR as taboo and young people as unequal to adults.

The results demonstrated widely-held positive perceptions of the importance of youth participation. Youth were seen as the leaders of tomorrow and as having an important role to play due to their ability to understand the needs of their

40 This work is licensed under a Creative Commons Attribution 4.0 International License. 
peers and relate to them more easily. Young people played an important role in the ASK programme, particularly in mobilising and sharing information with young people and in undertaking important supportive and administrative work, without which the programme could not operate. Assessing the form of MYP using the CHOICE flower, we can see that MYP in the ASK programme aligns most closely with the 'assigned but informed' form of participation. Young people were given meaningful roles in the programme. However, they had little choice over the form of their roles and were not involved in decision making.

Although young people sat on decision-making boards, they felt powerless and had no voting rights. This reflects findings in the same and similar programmes (Evelo \& Miedema 2019; Page, 2016). and falls short of definitions of MYP, which emphasise equality and involvement in decision making. The CHOICE model emphasises that there is not necessarily a hierarchy of forms of participation, and 'assigned but informed' is still one of the five 'petals' of the participation flower, meaning it is seen as a meaningful form of youth participation. However, it is a form of 'low responsibility' and one which falls short of the aspirations of young people themselves who are keen for more decision-making power. 'Progress' towards forms of participation where young people take on greater responsibilities seems to be challenged by two examples of a mismatch between aspirations and reality: the first at a community level, the second at a global level.

Firstly, the results demonstrate a mismatch between the aspirations of young people to be active decision-making agents and the reality of their position in Kenyan society. The deeply ingrained principles of respect for elders manifest themselves in expectations of strict obedience and discipline and young people occupying an inferior position to adults (Ahmed, 2011). The influence of this norm can be seen throughout the results, for example, in adult respondents' descriptions of youth as lazy, seeking hand-outs and not willing to work hard and young people describing themselves as despised by adults. Such findings are reflected in similar programmes in South Africa (Campbell et al., 2009; Mchakulu, 2007; AICAFMHA, 2008) and Latin America (Borden et al., 2006). The views of young people as unequal to adults clash with principles of MYP, which seek to empower young people and give them meaningful responsibilities. Intersectionality of both gender and ethnicity serve to present a further barrier as girls and those from clans other than those of the $\mathrm{CHC}$ leader face further barriers to involvement.

Young people's social position is closely linked to cultural views of marriage as the point of transition to adulthood (Pike et al., 2018). As the average age of marriage increases, young people's transition to adulthood is delayed, leaving young people in an extended 'waithood' (Honwana, 2014). This can limit the opportunities for MYP, particularly for young people over the age of 18 who are legally adults but socio-culturally still seen as children and therefore not expected to participate as adults. Kesby et al. (2006) describe this as a position of 'non-adults whose potential as social, civil and sexual actors is under-recognised. As van Reeuwijk and Singh (2018) argue, 'a rights-based approach which sees young people as active social agents is vital' for effective MYP (p. 217).

The second mismatch occurs at a global level, between the aspirations of the ASK programme and the reality of the context in which it is delivered. Reviewing the programme documentation, it is clear that the programme aspires to a medium or high level of responsibility for young people, one of the upper three 'petals' 'Youth Initiated Shared Decisions with Adults-High Responsibility' on the CHOICE Flower of Participation (CHOICE for Youth and Sexuality \& YOUACT, 2018). Young people's cultural position on a lower rung of the social ladder than adults is potentially at odds with aspirations of such youth-adult partnerships. A further clash may arise from the focus in MYP on young people actively participating in shared decision-making.

A certain level of critical thinking skills and empowerment are required to assert one's voice in fora such as a CHC. However, in the Kenyan education system, there is little focus on creative, critical thinking, and external pressures are prioritised over internal reasoning (Ahmed, 2011). This hegemonic approach can limit the potential for critical epistemic reflection and hence for youth empowerment (Wong et al., 2010; Hart et al., 1997).

41 This work is licensed under a Creative Commons Attribution 4.0 International License. 
The challenge of an assumed universalism of MYP reflects criticisms of the rhetorical use of 'participation' in HIV- and AIDS- an education which, as Miedema et al. (2011) argue, results in a focus on individual rights and entitlements without engaging in broader philosophical theories on rights or recognising of the significance of social relationships for individual wellbeing (Miedema et al., 2011).

\section{CONCLUSION}

Despite the two levels of mismatch between aspiration and reality at the community and global level illustrated in the results, the positive attitudes of both adults and young people towards the principle of MYP and the strides are taken towards involving young people in meaningful ways should be emphasised. The results demonstrated widelyheld positive perceptions of the importance of youth participation. Furthermore, it is important to note that the research was undertaken at an early stage in the programme, with organisations and communities that were new to the concept of MYP (van Reeuwijk and Singh, 2018). While it is important that both global- and community-level actors review the mismatches highlighted above, such achievements should not be underestimated.

The study puts forward recommendations that programmes aspiring to deliver effective and ethical MYP can be implemented at the individual, organisational and society/community levels. At the individual level, programmes should strengthen youth empowerment through mentorship, motivation, and (refresher) training, linking young people to funding opportunities and building young people's entrepreneurial skills. Organisations could increase young people's motivation through financial and non-financial incentives such as stipends, reimbursement of transport and lunch costs, income-generating activities and certificates for role performance.

At an organisational level, advocacy for MYP can support the integration and participation of young people in local health care management systems. Addressing barriers to MYP requires increased transparency, openness and inclusiveness in the establishment of key health care management structures. Institutions should establish built-in mechanisms for institutional support for MYP, including capacity building for young people. A specific number of positions should be allocated for young people and protocols should clearly define young people's roles, expectations and performance indicators.

Addressing the challenges of mismatch between global aspirations of MYP and local realities, international and local organisations should integrate an interrogation of social norms and the implications for MYP within programme design and development. This should include specific considerations of how norms relating to age interact with gender, class, ethnicity and socio-demographic characteristics (social, cultural and political environment). More specifically, managing expectations is key in the process. By jointly (organisations, community, adults and young people) defining MYP in the local context, acceptability could be increased. Programmes should recognise that the development of MYP with programmes is likely a slow process - especially in communities that are new to MYP - but that participation can be progressively expanded to yield a more acceptable, locally-owned and sustainable approach to MYP.

\section{ACKNOWLEDGEMENT}

The authors are grateful for the contributions of several people and organisations in the design and implementation of this study. Specifically, we would like to thank the SRHR Alliance partner$\mathrm{TICH}$, the young people and the research assistants who conducted the data collection exercise. We are grateful for the technical guidance provided by Rutgers, Simavi, the SRHR Alliance, and Globus Associates Questream.

\section{REFERENCES}

Ahmed, Z. (2011). Youth at the nexus: Ideology in HIV prevention in Nairobi, Kenya. Sex Education, 11(02), 129-154. doi:10.1080/14681811.2011.558422.

Arnstein, S. R. (1969). A ladder of citizen participation. Journal of the American Institute 42 This work is licensed under a Creative Commons Attribution 4.0 International License. 
of planners, 35(4), 216-224. 35 (4): 216-24. Finlay, S. (2010). Carving out meaningful spaces doi:10.1080/01944366908977225.

Australian Infant, Child, Adolescent and Family Mental Health Association (AICAFMHA). (2008). National Youth Participation Strategy Scoping Project Report. Stepney: Australian Infant, Child, Adolescent and Family Mental Health Association. http://www.copmi.net.au/i mages/pdf/Get-Involved/report_fact02.pdf.

Borden, L. M., Perkins, D. F., Villarruel, F. A., Carleton-Hug, A., Stone, M. R., \& Keith, J. G. (2006). Challenges and opportunities to Latino youth development: Increasing meaningful participation in youth development programs. Hispanic Journal of Behavioral Sciences, 28(2), 187 208. doi:10.1177\%2F0739 986306286711.

Campbell, C., Gibbs, A., Maimane, S., Nair, Y., \& Sibiya, Z. (2009). Youth participation in the fight against AIDS in South Africa: from policy to practice. Journal of Youth Studies, 12(1), 93109. doi:10.1080/13676260802345757.

CHOICE for Youth and Sexuality \& YOUACT. (2018). The Flower of Participation. CHOICE for Youth and Sexuality. https://www.youthdoit.org/assets/Uploads/2017 1122-Flower-of-Participation-Narrative.pdf.

Cornish, F. (2006). Challenging the stigma of sex work in India: material context and symbolic change. Journal of Community \& Applied Social Psychology, 16(6), 462-471. doi:10.1002/casp.894.

Evelo, J., \& Miedema, E. A. (2019). 'You don't want to come out from the crowd because you are a girl': gendered differences in young people's participation in sexuality education in Uganda. Sex Education, 19(2), 130-144. Doi:10.1080/14681811.2018.1506758 for youth participation and engagement in decision-making. Youth Studies Australia, 29(4), 53-59.https://search.informit.org/doi/epdf/10.33 16/ielapa.568641998471768

Freire, P. (1970). Pedagogy of the oppressed (MB Ramos, Trans.). New York: Continuum. https://libcom.org/files/Paulo\%20Freire,\%20M yra\%20Bergman\%20Ramos, \%20Donaldo\%20 Macedo\%20-\%20Pedagogy $\% 20$ of $\% 20$ the $\% 20$ Oppressed,\%2030th\%20Anniversary\%20Editio n\%20(2000,\%20Bloomsbury\%20Academic).pd $\mathrm{f}$

Hart, R. A. (1992). Children's participation: From tokenism to citizenship. Innocenti Essay No. 4. Florence: United Nations Environment Programme. https://www.unicefirc.org/publications/pdf/childrens_participation. pdf

Hart, R., Daiute, C., Iltus, S., Kritt, D., Rome, M., \& Sabo, K. (1997). Developmental theory and children's participation in community organisations. Social Justice, 24(3 (69), 33-63. https://www.jstor.org/stable/29767020

Honwana, A. (2014). 2 'Waithood': Youth Transitions and Social Change. In Development and Equity (pp. 28-40). doi:10.1163/9789004269729_004.

Howard, S., Newman, L., Harris, V., \& Harcourt, J. (2002). Moving from research" on" or" about" to research" with" or" by".... Exploring the roles of young people in educational research. In Australian Association for Research in Education Conference. University of Queenslan d. https://www.aare.edu.au/data/publications/20 02/how02535.pdf.

Kesby, M., Gwanzura-Ottemoller, F., \& Chizororo, M. (2006). Theorising other, 'other childhoods': Issues emerging from work on HIV in urban and

43 This work is licensed under a Creative Commons Attribution 4.0 International License. 
rural Zimbabwe. Children's Geographies, 4(2), 185-202. doi:10.1080/14733280600807039.

Mchakulu, J. E. J. (2007). Youth participation in radio listening clubs in Malawi. Journal of Southern African Studies,33(2), 251-265. doi:10.1080/03057070701292574.

Miedema, E. A., Maxwell, C., \& Aggleton, P. (2011). Education about HIV/AIDStheoretical underpinnings for a practical response. Health Education Research, 26(3), 516-525. doi:10.1093/her/cyq088

Oliver, K. G., Collin, P., Burns, J., \& Nicholas, J. (2006). Building resilience in young people through meaningful participation. Australian eJournal for the advancement of Mental Health, 5(1), 34-40. doi: 10.5172/jamh.5.1.34

Page, A. (2016). Navigating Liminal Spaces: An Examination of the Impacts of Youth Group Participation on Young People's Social Exclusion in Rural Western Kenya. Master's Thesis, University of Amsterdam. https://educationanddevelopment.files.wordpres s.com/2013/11/anna-page-2016.pdf
Pike, I., Mojola, S. A., \& Kabiru, C. W. (2018). Making sense of marriage: Gender and the transition to adulthood in Nairobi, Kenya. Journal of Marriage and Family, 80(5), 1298-1313. doi:10.1111/jomf.12525 .

Van Reeuwijk, M. \& Singh, A. (2018). Meaningful Youth Participation as a way to achieving success. Canadian Journal of Children's Rights/Revue canadienne des droits des enfants, 5(1), 200-222. doi:10.22215/cjcr.v5i1.1301.

Villa-Torres, L., \& Svanemyr, J. (2015). Ensuring youth's right to participation and promotion of youth leadership in the development of sexual and reproductive health policies and programs. Journal of Adolescent Health, 56(1), S51-S57. Doi: 10.1016/j.jadohealth.2014.07.022

Wong, N. T., Zimmerman, M. A., \& Parker, E. A. (2010). A typology of youth participation and empowerment for child and adolescent health promotion. American journal of community psychology, 46(1), 100-114. doi: 10.1007/s1046 4-010-9330-0. 